\title{
Introducing the Basic Variety
}

\section{Peter J ordens Vrije Universiteit Amsterdam}

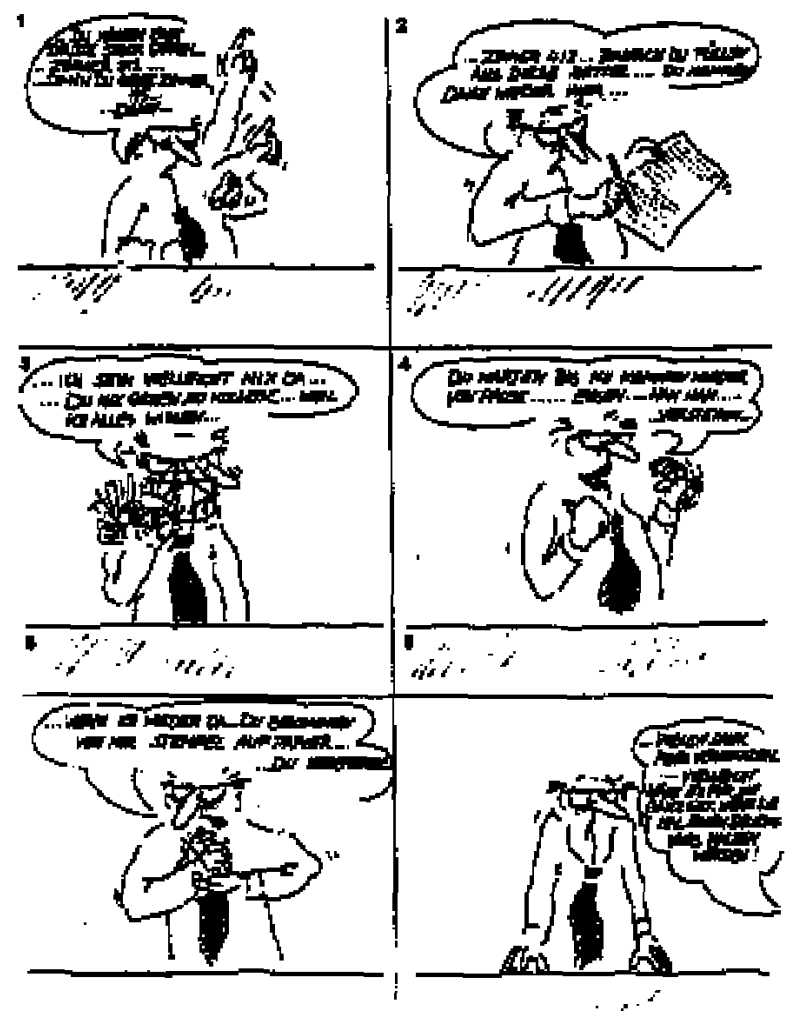

1 ... you have to first

third floor go ...

... room $312 \ldots$...

.... then you go room

$195 \ldots$

... then . . .

$3 .$. I be probably no there ...

... you no go to colleague... . because I everything know ...

5 ... when I back here ... you get from me stamp on paper...

... you understand ...
2 ... room $412 \ldots$ afterwards you fill in this form .... you come then back here...

4 you wait until I come back from break ..... . eat. ... yum yum ..... ... understand . . .

6 ... thank you very much everything's absolutely clear ..... it might be good for you, though, if you took a German course! 


\section{The B asic Variety: core properties}

From the very beginning of their language acquisition process, adult L 2 learners are able to communicate. A s soon as they know a few target language words, they also know how to use these words appropriately in discourse. R emarkable as this is, it has never been an area of extensive research. Some attention has been paid to the emergence of formal devices in early discourse, as in H atch (1978), but as far as structural principles are concerned no extensive studies have been carried out. A lthough it might seem obvious that utterances with only a few constituents are not very interesting from a structural point of view, K lein and Perdue (henceforth $K \& P$ ) prove this idea wrong.

Perdue (1996) has recently demonstrated how L 2 learners are able to communicate with one-constituent utterances denoting activities and objects and that even verbless utterances with a few noun-like constituents are structured in terms of topic-focus patterns interacting with semantic constraints and scope relations. It is this 'interplay of semantic and discourse-organizational constraints' which also governs 'much more advanced learner production' (Perdue, 1996: 143, 146). Whereas L 2 learners are able to apply these types of organizational constraints from very early on, there is no reason to assume that at the relevant stage words like gehen ('go'), spazier ('stroll'), laufa ('run'), komm ('come'), denoting activities corresponding to verbs in the target language, also have syntactical verb status in the learner's language. B ecause there is no verb-argument structure at the initial stages 'the distribution of these words here is not that of the TL' (142).

In a further stage of acquisition noun-like constituents become organized around a 'verb-like' element. Examples are utterances such as Chaplin gehen strasse ('Chaplin go street'), gehen spazier ('go stroll'), komm strasse ('come street'), das frau laufa schnella strasse ('woman run fast street'). A that point utterances are structured by phrasal patterns, too. What intrigues most, however, is what it is that urges the learner to give up the noun-based structure, and what it is that constrains the organization of 'major constituents (...) around the verb' (Perdue, 1996: 144). These are the core questions of the present volume.

In the main contribution of this volume $K \& P$ show that at the relevant stage all learners produce simple utterances with a few constituents organized around the verb. For all learners, no matter what their mother tongue or target language, these utterances are based on the same organizational principles. Furthermore, K\&P argue that this particular organizational system is stable in the sense 
that it is resistant to developmental progress. For reasons of simplicity and stability, $K \& P$ call this type of language used by $L 2$ learners 'the Basic Variety' (henceforth BV) and one may wonder why it is that natural languages are not all instantiations of the BV.

A Ithough the BV lacks the structural properties of fully fledged languages, such as the grammatical categories 'subject' and 'object', the lexical categories 'noun' and 'verb', as well as verb-argument structure, learners can express temporal and spatial relations. They are able to relate the time span about which they want to make an assertion to the time of utterance. In other words they can express 'before', 'after' and 'simultaneously'. They can also express duration, habituality or iterativity of time spans. They are able to distinguish between types of situation such as 'states' and 'dynamic events' and between spatial relations such as 'location' and 'change of location'.

Characteristic of the approach taken by $K \& P$ is that systematicity does not follow from strong theoretical presumptions of any kind. This does not mean that the organizational principles have no theoretical foundation. $\mathrm{O}$ the contrary, it is the interplay between pragmatic, semantic and phrase structure constraints with their own theoretical embedding which can account for the types of form-meaning correspondences in learner varieties.

\section{The BV and the human language faculty}

The approach of looking at learner varieties as systems in their own right has found its proponents within the framework of 'creative construction' (Dulay et al., 1982) and 'interlanguage theory' (Selinker, 1972). Within this tradition of second language research it is assumed that L 2 learners process L 2 data on the basis of language learning mechanisms which are part of the human language learning faculty. 0 ther researchers such as Schachter and Rutherford (1979) have argued for the role of crosslinguistic influence. They provide evidence for the role of $L 1$ typological properties as part of the inherent structural characteristics of the learner system. H ence, utterances by Chinese learners of E nglish, such as I rrational emotions are bad but rational emotions must use for judging or These ways almost can classify two types, are not to be interpreted as ill-formed English passives, but rather as realizations of underlying L 1 topic-comment structure. Within this tradition of looking at learner varieties as coherent linguistic systems, the BV has a particular status. It is a simple language system, in terms of its organizational principles. Form-function correspondences are determined by three types of constraints: 
phrasal constraints which define the patterns in which lexemes may occur, semantic constraints which attribute arguments to particular positions (controller first) and pragmatic constraints which organize information in connected discourse (focus last). The BV, however, is more than just a simple language system. It is a highly functional means of communication which is similar for many learners for a long period. A s such it is a 'genuine manifestation of the human language faculty' (K lein, 1997: 5) which means that the limited set of organizational principles inherent to the $\mathrm{BV}$ belongs to the genetical endowment of our species. Compared to fully fledged languages, Klein considers the BV even to be 'the core manifestation of the human language faculty' (K lein, 1997: 5). Hence, 'rather than taking [fully fledged languages] as a point of departure and working back in trying to understand how acquisition works' ( $K \& P$, this volume: 000$)$, the study of second language acquisition has the best prerequisites to provide insights into the nature of the human mind.

One might argue about the exact form of the particular constraints. Comrie (this volume), for example, doubts whether N PV-N P order is typical of the BV in all L 2 settings. He suggests that it may reflect salient word order of the target languages that were part of the project, i.e., English, German, Dutch, French and Swedish. On the other hand, if saliency were responsible, one might ask why children learning German and Dutch choose NP-NP-V as their main pattern of utterance structure (K lein, 1974; Clahsen, 1988; J ordens, 1990). Furthermore, with Turkish learners of $G$ erman and D utch and Punjabi learners of E nglish there is a shift from L 1induced N P-NP-V to NP-V -NP. The question is, do they really shift or do they use both NP-V -NP and NP-NP-V as alternatives in different conditions?

Discussions about the actual form of the constraints, however, do not affect the central role of the organizational principles in learner varieties. In fact, one may expect similar principles to be found in simple varieties of fully fledged languages, such as telegraphic speech, headlines and captions. With respect to case marking in G erman headlines, for example, the principle of 'degree of control' seems to interact with principles of 'fore- and backgrounding' (J ordens, 1992). This explains why in verbless utterances such as D en HSV fest im G riff (the-A CC Hamburg SV firmly in-the grip) the accusative is used. The entity which is in control, i.e., the agent, is marked with the nominative. This entity is implied by G riff. Since it is not expressed, the structure only has the accusative NP. In D er H SV fest im G riff von Hajduk Split (the-NOM Hamburg SV firmly in the grip of $\mathrm{H}$ ajduk Split), however, the agent is backgrounded as 
part of the von-phrase. This explains why the only NP which is left foregrounded is marked with the nominative.

\section{The linguistic status}

A s far as its formal properties are concerned, $K \& P$ argue that the BV can be seen as an I-language, i.e., an instantiation of U G. It is a stable system that is the result of the human language faculty and second language input. Within Chomsky's minimalist framework the BV can be characterized as an I-language in which all (formal) features are weak. This is why it has no inflectional morphology and no movement. In order to become a fully fledged language, particular features have to be 'strengthened' either by the identification of principles underlying manifestations of movement or by the acquisition of morphology.

$B$ ierwisch (this volume) goes into the question of whether the $B V$ of $L 2$ learners originates from the same human language faculty as is the case with fully fledged languages of $L 1$ learners. $H$ e argues that the BV essentially differs from the way in which I-languages are instantiations of $U \mathrm{G}$. For B ierwisch the $\mathrm{BV}$, and thereby second language learning, is based on general cognitive strategies, whereas I-languages are based on resources which are language-specific. A s opposed to $K \& P^{\prime} s$ argument of the BV being a simplified version of a normal I-language, Bierwisch argues 'if strong features are expensive, and hence avoided by L 2 learners, there is no reason why this tendency to avoid strong features should not be equally effective in $L 1$ acquisition, and hence a driving force in language change' ( $p .000$ ). In SL A research, B ierwisch's position is a familiar one (see, amongst others, Felix, 1985; B ley-V roman, 1989; Clahsen, 1984). However, it has never been discussed with the formal precision of the properties of an I-language and the types of constraints inherent to the BV.

$B$ oth Bierwisch and $M$ eisel (this volume) raise specific questions with regard to the characterization of the BV as an I-language. L 2 learner languages seem to have properties which do not occur in Ilanguages. Meisel, for example, argues that in L 1 acquisition of German, non-finite verb forms never move, whereas in L2 acquisition infinitival verb forms do occur in verb-second position (p. 000). Furthermore, he notes that, if the BV has the status of an I-language, why should it not be analysable 'in terms of the same categories and relations as fully fledged languages?' (p. 000). Finally, M eisel discusses developmental differences between $L 1$ and $L 2$ acquisition. If $U G$ is available to $L 2$ learners, why does fossilization occur? 
From an entirely different point of view, Comrie (this volume) also discusses the question of whether the $\mathrm{BV}$ can be seen as a real language. Whereas, according to Comrie, native languages have both a social (communicative) and a cognitive function, the BV only functions communicatively: ' $O$ ne has to be very proficient in a second language before one is prepared to use that language, rather than one's native language, as one's basic conceptual tool' ( $p .000$ ). $\mathrm{H}$ ence, he characterizes the BV as a 'second-language pidgin' which serves as 'a highly efficient system of communication' (p.000).

\section{Issues in second language research}

Within the coherent framework of its organizational principles, the $B V$ has the potential to provide answers to long-standing questions.

1 Why do learners fossilize?

The BV provides an explicit account of what constitutes a simple language system in terms of the organizational principles involved. It represents 'a potential fossilization point' due to the fact that it is not only a simple but also a stable system. The BV is a type of interlanguage system in which conflicts between constraints, i.e., possible sources of instability, are avoided. For example, $D$ ative $M$ ovement does not occur in the BV of E nglish and Indirect $O$ bject Cliticization does not occur in the BV of $F$ rench because these types of movement are in conflict with the constraint theme before relatum in target position (SE M 3; K \& P, this volume:000). B ierwisch (this volume), however, has his doubts whether learner varieties would not allow constraints to be in conflict. If that were true, socalled psych verbs should be absent from the BV across interlanguages. Psych verbs such as please, remind or convince in utterances like The proposal pleased J ohn, The book reminds me of my childhood and The argument convinced Bill violate the constraint according to which 'T he N P-referent with highest control comes first' (SE M 1; K \&P, this volume: 000). The same would hold for verbs such as receive or borrow in utterances like She received a letter from her sister and $\mathrm{He}$ borrowed a book from his colleague. $\mathrm{H}$ ere the constraint ' $\mathrm{C}$ ontroller of source state outweighs controller of target state' (SE M 2; K\&P, this volume: 000 ) is violated. Finally, utterances such as The box contains three apples which violate the principle of 'Theme before relatum in target position' (SEM 3) ought to be absent from the BV. Whereas Bierwisch wonders whether these predictions are borne out, there is empirical evidence from foreign language learners of English who are unwilling to 
accept utterances violating the semantic constraints just mentioned. This holds for utterances with the psych verbs surprise and strike as in The news surprised me and John strikes me as pompous violating SE M 1, as well as for utterances such as This tent sleeps five people, The pond is leaping with frogs and This lake drowned our cat violating SE M 3. Finally, learners seem to avoid the violation of SEM 2 with verbs such as receive, buy and borrow by leaving the 'controller of the source state' unexpressed. These observations from foreign language learners have been interpreted post hoc in terms of markedness conditions. Within the framework of the BV, however, they provide empirical evidence for the claim that learner varieties tend to be systems in which conflicts between constraints are indeed avoided.

\section{When do constraints of the source language come into play?}

The BV leaves room for crosslinguistic influence only in the early stages of acquisition. Furthermore, with reference to $B$ roeder et al. (1993a; 1993b) and Schenning and van H out (1994), K \& P note that the source language generally comes in where the target language system has alternative ways of expressing the same content. When more options are available, $\mathrm{L} 2$ learners seem to take the alternative closest to their $L 1$. This seems to hold for head-complement and complement-head structure in D utch. In D utch, complex N Ps have complement-head structure in compounds as in afdelingshoofd (department head), while they have head-complement structure in N P PP phrases as in chef van de afdeling (head of the department). B roeder (1993) has observed that in L2 D utch, Turkish informants prefer to use compounds or complex NPs with complement-head structure as in sigarettenwinkel (cigarette shop), winkelbaas (shop boss), while Moroccan subjects choose the N P PP equivalent with head-complement structure as in winkel van sigaret (shop of cigarette), baas van winkel (boss of shop). This also holds for such complex N Ps with pronominal possessives as zijn boek (his book) vs het boek van hem (the book of his) and complex NPs with nominal possessives as mijn vader's broer (my father's brother) vs de broer van mijn vader (the brother of my father). Here, Turkish informants have no problem in acquiring pronominal possessives with complement-head structure such as mijn tas (my bag) and zijn familie (his relatives). M oroccans, however, use personal pronouns instead of possessives as in hij vrouw (he wife) and mij koffertje (me case). Finally, in those cases in which Turkish learners use nominal possessives, they also use the complement-head structure of the less frequent $D$ utch alternatives with a preposed genitive NP 
vader zus (father sister). The M oroccan subjects, on the other hand, choose the more common N P PP equivalent with head-complement structure broer van vader (brother of father). If the learner's option in these cases is adequately represented in terms of headcomplement vs complement-head structure, one may also expect $L 2$ learners of Dutch and German to choose between either SOV or SVO structure as their basic phrasal pattern. The data seem to suggest that this is true. NP-NP-V is found in Turkish learners of $D$ utch and German and not in Moroccan learners of Dutch or in I talian learners of $\mathrm{G}$ erman. The same holds for Punjabi learners of English who seem to use the NP-NP-V pattern, too. U se of L 1similar structures here may be induced by the fact that English also has instances of complement-head structure. Examples are nominal compounds such as dishwasher and can opener and possessives such as my father's book.

Schwartz (this volume) particularly discusses the claim of the BV that all L2 learners at some point in acquisition 'create interlanguages that are at the core structurally identical' (p. 000). $O n$ the one hand, she argues for variation due to $L 1$ influence. The use of SOV by Punjabi and Turkish speakers as well as the use of subordination by Spanish-speaking learners of L 2 French (p. 000), she sees as evidence that $L 1$ grammar imposes analyses on the target language input data. Furthermore, she argues that structural similarities of the $B V$ of $L 2$ learners 'reflect properties of the [target language] input' (p. 000).B oth these arguments are legitimate. They urge the closer analysis of, for example, SO V L lers acquiring SOV L 2 as opposed to SVO L 2. It would be interesting to see if, as Schwartz puts it, L 1 grammar 'gives way' to the phrasal patterns of the BV 'in blatant disregard of the input' (p. 000).

\section{How to explain development towards the target?}

G iven $K \&$ P's claim that learner languages tend to stabilize at some point at which constraints are not in conflict, the question remains as to what mechanisms may propel further development of the language acquisition process. As $K \& P$ argue, answering this question may provide insight into why it is that natural fully fledged languages are as complex and as diverse as they are.

E arlier research on the acquisition of word order in German has shown that learner languages develop along similar lines of progression, in that all learners appear to go through the same stages of acquisition (see Meisel, Clahsen and Pienemann, 1981; Clahsen et al., 1983). The question of how to explain the order of acquisition has attracted much research. Essentially, there are two 
opposing views to explain development: on the one hand, the use of differing strategies operating on surface structures (see Pienemann, 1987; Clahsen, 1984); on the other hand, the restructuring of the underlying system (see J ordens, 1988; Schwartz, 1996). In both cases the question of the driving force has never been explicitly posed, probably because 'exposure to the target language' is regarded as trivial. However, since the actual route can be described in terms of ordering conditions according to which the acquisition of $Y$ implies the acquisition of $X$, there is at least reason to question why it is that $X$ is learnt before $Y$. If it is the use of strategies which determines $L 2$ learning, ordering could be explained by degree of complexity. If there are structural reasons at play, ordering could be explained by the notion of 'prerequisite knowledge'. H ence, for example, having learnt verb-argument structure, headedness (particle rule) has to be learnt before verb movement, verb movement has to be learned before or simultaneously with finiteness and verb-second (inversion) has to be learnt before or simultaneously with verb-end. The fact that 'exposure to the target language' is seen as the driving force becomes evident from the use of notions such as 'triggering' or 'parameter setting'.

Even though it is obviously the case that exposure to the target language has an influence on the way in which learner languages develop, one may still wonder whether it constitutes the actual driving force. Since the BV is an extremely functional means of communication with a high degree of stability, one should expect intrinsic reasons for development to exist. Crucial for the development of the $B V$ are, according to $K \& P$, 'discourse contexts (...), where its constraints come into conflict'. In such a situation the learner has two possibilities: either to " "override" one of the constraints, or (...) develop specific means to accommodate the "competition" ' (p. 000). In the latter case, as Comrie (this volume) puts it: 'the language may develop syntactic complexity as a means of indicating what is being sacrificed, such as a passive voice to indicate that the subject is not the agent' (p.000).

The passive as a means to overcome a conflict between constraints seems to play an important role as a driving force in second language acquisition. In a study by Zobl (1988) on the acquisition of English by L 1 J apanese speakers, the acquisition of the passive turns out to have enormous consequences with respect to the structure of the current interlanguage system. It is the acquisition of the passive that makes Japanese learners 'realize' 'that the initial assumption of free word order for direct objects in the English VP is untenable' (van B uren, 1996: 202). This insight is 
what van Buren calls a 'catastrophic learning experience'. It leads to a fundamental restructuring of the current interlanguage system into a system with strict adjacency. In general, it leads to the restructuring of a non-configurational language into a configurational language in which, for NPs to occur in non-base positions, movement is required.

A nother example of a conflict leading to complexity is given in Perdue (1990). Here, it is shown that in an utterance such as a dame qui a volé le pain (is the woman who has stolen the bread) it is the violation of the constraint of chronological order which motivated development of the passé composé (see $K \& P$, this volume: 000 ).

The examples given illustrate that conflicts between constraints are a prominent driving force towards target language complexity. A nother motivation for syntactic development is the need to solve structural ambiguities. This is, I assume, the reason why learners progress from a system of non-finite utterance organization - in which major constituents are organized around the verb - to a system in which these constituents become categorized in terms of their syntactic functioning. Categorization in terms of syntactic functions such as subject, object, predicate, noun, verb, adjective etc. is a means of solving structural ambiguity. It implies hierarchical structuring. Hierarchical structure can be acquired inductively. A s K lein (1991) pointed out, this is due to the fact that the process of acquisition is accumulative in nature. Furthermore, I assume that substitution also plays a major role in identifying hierarchical structure. It exemplifies the way in which constituents are grouped together at different levels of syntactic complexity. Hierarchical structuring is crucial for language development, in that it provides learners with a tool which is both highly efficient and communicatively powerful. It allows learners not only to get rid of structural ambiguities, but also to make use of structural dependency (as in wh-questions) and recursivity (as in embedding).

\section{Summary}

R esearch of the BV is the study of the mechanisms driving second language acquisition. On the basis of a detailed analysis of the learner languages of 40 adult immigrant learners of English, German, Dutch, French and Swedish, K\&P show that the BV is a simple language system in which linguistic principles that are part of I-grammar interact with organizing principles of a pragmatic and semantic nature. These principles, they argue, are universal across $\mathrm{L} 2$ learners and as such they may belong to 'the genetic endowment of our species' ( $K \& P$, this volume: 000 ). This analysis of the 
structure of learner languages is reason for $\mathrm{K}$ lein to regard fully fledged languages as 'borderline cases' in the sense that they 'exploit the structural potential of the human language faculty to a particularly high extent' (K lein, 1997: 5). By contrast, however, learner varieties as studied in second language research are to be considered as 'a genuine' and even 'the core manifestation of the human language faculty' (K lein, 1997: 5).

\section{R eferences}

B ley-V roman, R . 1989: What is the logical problem of foreign language learning? In Gass, S.M. and Schachter, J., editors, L inguistic perspectives on second language acquisition, Cambridge: Cambridge University Press, 41-68.

B roeder, P. 1993: Talking about people: a multiple case study on adult language acquisition. A msterdam: Swets and Zeitlinger.

B roeder, P., E xtra, G. and van H out, R. 1993a: R ichness and variety in the developing lexicon. In Perdue, C., editor, A dult language acquisition: cross-linguistic perspectives. Volume 1, Field methods, Cambridge: Cambridge U niversity Press, 145-63.

B roeder, P., Extra, G., van Hout, R. and Voionmaa, K. 1993b: Word formation processes in talking about entities. In Perdue, C., editor, A dult language acquisition: crosslinguistic perspectives. Volume 2, The results, Cambridge: Cambridge U niversity Press, 41-72.

Clahsen, H. 1984: The acquisition of German word order: a test case for cognitive approaches to L2 development. In A ndersen, R., editor, Second language: a cross-linguistic perspective, R owley, M A : N ewbury H ouse, 219-42.

---- 1988: Parameterized grammatical theory and language acquisition: a study of the acquisition of verb placement and inflection by children and adults. In Flynn, S. and O 'N eill, W., editors, Linguistic theory in second language acquisition, D ordrecht: K luwer, 47-75.

Clahsen, H., Meisel, J.M. and Pienemann, M. 1983: Deutsch als Z weitsprache: der Spracherwerb ausländischer A rbeiter. Tübingen: G unter Narr.

D ulay, H .,B urt, M . and Krashen, S.D. 1982: L anguage two. O xford: 0 xford U niversity Press.

Felix, S.W. 1985: M ore evidence on competing cognitive systems. Second $L$ anguage Research 1, 47-72.

H atch,E .M. 1978: Second language acquisition:a book of readings. R owley, $M A$ : N ewbury House.

Jordens, P. 1988: The acquisition of word order in Dutch and German as $L 1$ and L2. Second L anguage Research 4, 41-65.

---- 1990: The acquisition of verb placement in Dutch and German. L inguistics 28, 1407-48.

---- 1992: The cognitive function of case marking in $G$ erman as a native and a foreign language. In Gass, S.M. and Selinker, L., editors, 
$\mathrm{L}$ anguage transfer in language learning, $A$ msterdam: John B enjamins, 138- 75 .

Klein, R.M. 1974: Word order: Dutch children and their mothers. Publicaties van het Instituut voor Algemene Taalwetenschap: Universiteit van A msterdam 9. A msterdam: Instituut voor A Igemene Taalwetenschap.

Klein, W. 1991: Seven trivia of language acquisition. In E ubank, L., editor, Point counterpoint. Universal Grammar in the second language, A msterdam: John B enjamins, 49-78.

---- 1997: Learner varieties are the normal case. Clarion 3, 4-6.

Meisel, J.M., Clahsen, H. and Pienemann, M. 1981: On determining developmental stages in natural second language acquisition. Studies in Second $L$ anguage A cquisition 3, 109-35.

Perdue, C. 1990: Complexification of the simple clause in the narrative discourse of adult language learners. L inguistics 28, 983-1009.

---- 1996: Pre-basic varieties: the first stages of second language acquisition. In Kellerman E., Weltens, B. and B ongaerts, T., editors, E urosla 6: a selection of papers, A msterdam: VU U itgeverij, 135-49.

Pienemann, M. 1987: Psychological constraints on the teachability of languages. In Pfaff, C.W., editor, First and second language acquisition processes, Cambridge, M A : N ewbury H ouse, 143-68.

Schachter, J. and R utherford, W. 1979: D iscourse function and language transfer. Working Papers in Bilingualism 19, 1-12.

Schenning, S. and van H out, R. 1994: D imensional spational relations in adult language acquisition. In Bok-Bennema, R. and Cremers, C., editors, L inguistics in the Netherlands, A msterdam: John Benjamins, 235- 46.

Schwartz, B.D. 1996: Parameters in non-native language acquisition. In Jordens, P. and Lallemann, J., editors, Investigating second language acquisition, B erlin: M outon de G ruyter, 211-35.

Selinker, L. 1972: Interlanguage. International Review of Applied $L$ inguistics 10, 209-31.

van B uren, P. 1996: A re there principles of U niversal Grammar that do not apply to second language acquisition? In J ordens, P. and L alleman, J., editors, Investigating second language acquisition, Berlin: M outon de G ruyter, 187-207.

Zobl, H . 1988: Configurationality and the Subset Principle: the acquisition of $V^{\prime}$ by Japanese learners of English. In Pankhurst, J., SharwoodSmith, M. and van Buren, P., editors, L earnability and second languages: a book of readings, Dordrecht: Foris, 116-31. 